\title{
Corpus Pattern Analysis of of-Construction Phrase Transformations to the Genitive
}

\author{
Ai Inoue ${ }^{1}$ \\ ${ }^{1}$ Department of Foreign Languages, National Defense Academy, Japan \\ Correspondence: Ai Inoue, Department of Foreign Languages, National Defense Academy, 1-10-20 Hashirimizu, \\ Yokosuka City, Kanagawa Prefecture, 239-8686, Japan. E-mail: aiinoue@nda.ac.jp
}

\author{
Received: July 20, $2020 \quad$ Accepted: August 24, $2020 \quad$ Online Published: August 28, 2020 \\ doi:10.5539/ijel.v10n6p118 URL: https://doi.org/10.5539/ijel.v10n6p118
}

\begin{abstract}
While it is well known that phrase transformations take place, there has been very little concrete research on phrase transformations and the associated rules. To go some way to filling this gap, this paper used corpus pattern analysis (CPA) to examine of-construction phrases, as exemplified by on the face of it and on its face, and elucidate the syntactic manipulation in the semantic and functional features of on its face. The CPA revealed that on its face was semantically the same as on the face of it (i.e., seemingly), but that the meaning of face, i.e., appearance, had more stress in the on the face of it phrase than the end-focus. Further, on its face was found to more often co-occur with legal lexical items such as constitutional, invalid, and lawful, and to be used more often in legal contexts. The reason on its face was derived from on the face of it was found to be because of the end-focus and the influence of semantically compatible phrases, such as for the sake of $\sim$ and for $\sim$ 's sake, on behalf of $\sim$ and on $\sim$ 's behalf. However, it should be noted that not all phrases that have of-constructions can be transformed into the genitive; for example, for the life of me does not transform into * for my life because * for my life is most often literally interpreted. It appears that linguistic economy is the most probable reason for phrase transformations from of-constructions to genitive constructions.
\end{abstract}

Keywords: phraseology, phrase transformation, corpus pattern analysis (CPA), of-construction, possession

\section{Introduction}

This study is part of a larger phraseological project focused on determining the rules for phrasal change through corpus pattern analysis (CPA) examinations of contemporary English examples.

Bybee (2015) stated that any research on language change should focus on individual lexical items to expose the reality of the language changes; however, both individual lexical items and phrases can change. For example, Inoue (2020b in press) discussed the interchangeability of those that and they who with those who when referring to people, and in an earlier paper revealed how the well-known fixed use idiom take care of transformed into take care for because they were semantically similar phrases (See Inoue, 2018a). Inoue (2020a in press) also recently concluded that the prepositional changes in phrases such as in accordance to were the result of the merging of in accordance with and according to. While these changes are observable, unlike other language changes, there has been little research on such transformations/changes, possibly because of: (i) ambiguous phraseological unit definitions; and (ii) difficulties in separating such phrase changes. While it appears that these phrases change randomly, it is assumed that there must be some rules for these types of phrase changes because all language changes have their own clines toward either grammaticalization or degrammaticalization.

This study examines phrase changes using the example in (1), that is, on the face of it $->$ on its face, (italicized by the author), and discusses how on the face of it changed into on its face. Unlike previous research that has regarded on its face as erroneous, in this paper, it is seen as part of language change and therefore correct.

(1) a. The Anti-Riot Act, on the other hand, appears to be unconstitutional on its face, but has been challenged only a few times because it's so rarely used, he said.

(COCA, 2019, NEWS)

b. ..., a proposed Executive Order is lawful on its face and properly drafted.

(COCA, 2017, MAG)

c. He said the plan "seems absurd on its face."

(COCA, 2016, MAG)

The CPA revealed that because of its high frequency and wide dispersion, on its face was not a mistakenly used phraseological unit, and was most often used in the pattern [a copular verb + words related to the law (e.g., 
unconstitutional, invalid, etc.) + on its face $]$ in legal discourses. Other patterns, such as [a copular verb + a semantically negative word such as absurd, bad, etc. + on its face] were also observed. On its face in both patterns means it looks like, which is indistinguishable from on the face of it, with the only difference in meaning being that the semantic focus moves from the it in on the face of it to face in on its face, that is, the function of face (i.e., appearance) is stronger than in on the face of it. The reason for the phrase change is because of a shift in the semantic focus and the influence of the interactive use of the phrase. Similar examples are for the sake of $\sim$

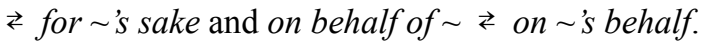

This paper has ten sections. Section 1 reviews the current research into phrase changes and presents the research foci, Section 2 examines English phraseology research in a literature review and specifically examines on the face of $i t$ and its construction, and Section 3 introduces the research questions based on the review in Section 2. Section 4 details the research method adopted in this study, Section 5 introduces the corpora used, Section 6 discusses the research results, and Section 7 investigates the degree to which the research results are supported using a substitution test on native English speakers. Section 8 verifies similar changes in other phrases, Section 9 reveals the study implications, and Section 10 summarizes the study.

\section{Literature Review}

Because English phraseology has been researched from many standpoints, there remains some ambiguity as to the formations and transformations. Therefore, to overcome this ambiguity, this section first explains English phraseology and then focuses on the phrase on its face, which is a variant of on the face of it, through a careful examination of on the face of it to make the relationship clear between the genitive (i.e., on its face) and the of-construction.

\subsection{English Phraseology—Definition and Problems}

There does not appear to be any clear-cut, non-controversial definitions for English phraseology. A vague definition would be that English phraseology is the study of phrases; however, this definition is unsatisfactory as it does not indicate the phrasal inclusions. This study, therefore, defines English phraseology as the study of repeatedly used phrases of at least two words and includes word-combinations such as idioms, collocations, phrasal verbs, proverbs (= sayings), formulae, discourse particles and fixed phrases. While the common umbrella term for these types of word-combinations is phraseological units (PUs), with the less common term phraseme having the same meaning, as with the definition, the terminology has tended to vary depending on the targeted word-combinations. Therefore, this study defines each word-combination based on frequency, polysemy, semantic transparency and commonly used definitions. However, this study does not intend to fully explain the definitions for each word-combination by comparing them with discussions in previous research.

In infrequently used idioms such as keep one's head, the meaning is not the sum of each component as these are not polysemous word-combinations. While collocations such as set up/launch a company range from high frequency to low frequency, they are not polysemous and are semantically easy to predict from each component; for example, to set up a company is more often used than to launch a company. Phrasal verbs, which are frequently used, are word-combinations comprising either a verb and an adverb or a verb, an adverb (optional) and a preposition, but are not polysemous word-combinations. Semantically, however, the meaning of a phrasal verb is not always the sum of each component; for example, look up to and put off are phrasal verbs. Formulaic phrases such as now you're talking, thank God/Goddess, it's Friday. and I wasn't born yesterday are often used in conversations, but do not have polysemy, with some being semantically easy to understand, but others not. Proverbs (= sayings) such as don't teach your grandmother to suck eggs, which are not the sum of each component from a semantic perspective, are used in limited contexts, and are neither frequently used nor polysemous word-combinations.

Discourse particles such as you know, I mean and let's see have a high frequency when used in a conversation and have polysemy and can have both a literal meaning and a pragmatic meaning depending on the context, with some such as after all and stuff like that being more semantically difficult to understand as the meaning is not a sum of each component and they are not polysemous word-combinations. Fixed phrases, such as you know what, here we go (again) and let's say (Inoue, 2007), generally have high frequency and polysemy, with some fixed phrases such as until before and until by being monosemous (the antonym of polysemous) (Inoue, 2019). Both monosemous and polysemous fixed phrases have tended to be overlooked in the literature as they are beyond the existing English language theories and grammar rules.

PUs can be classified into two categories: those that can be explained using existing grammar rule/theories (i.e., idioms, collocations, phrasal verbs, formulae, proverbs and discourse particles); and those that are irregular and cannot be explained using existing grammar rules/theories (i.e., fixed phrases). 
A review of previous English phraseology research revealed two main research problems. The first problem is the absence of a clear English phraseology definition as to date except for Inoue (2018b), who suggested some possible conditions and criteria, there have been no systematic frameworks developed for phraseological research to explain the process by which a word-combination becomes an independent PU. The second problem is that no research on irregular PUs has been actively conducted for several reasons. (i) Because idioms rarely change, idiomic development has not have not been fully discussed, which means that the explanations and descriptions in dictionaries remain the same. However, there are often several variants of an idiom; for example, take care for, take care about and care of are all derived from the well-known idiom take care of (Inoue, 2018a); therefore, idiom research has tended to neglect current idiom transformations. (ii) No clear standards are available for fixed phrases, such as you know what, until to and up until to to decide which word-combinations are fixed phrases (Inoue, 2007; Inoue, 2011). Consequently, as there has been limited research on fixed phrases, there are insufficient explanations in dictionaries.

\subsection{On the Face of it and on its Face ${ }^{l}$}

There has been a consensus in previous research that the phrase on the face of it used to mean 'it looks like' as in (2), with (3) giving examples of on the face of it obtained from the data introduced in Section 5.

(2) a. used for saying that something appears to be true but might not be true when examined it in more detail: We do not believe on the face of it that there has been illegal activity by the banks. $\left(M E D^{2}\right)$

b. on [upon] the face of it it looks like $\sim$ (original in Japanese) On the face of it the document seemed genuine. (Ando (ed.) 2011, p. 542)

c. on the face of it is a phrase used for saying it looks like (original in Japanese)) $\left[B B I^{2}\right]$ On the face of it, the Paynters are a dull, middle-class couple. But it is a façade. -LDEI (Konishi (ed.) 2001, p. 565)

(3) a. The inventory of used aircraft was too high, and it created a disparity in value that hurt sales of new planes, he said. It may seem tantalizing to use this tax deduction as a way to get a free plane, but it's not that simple. On the face of $i t$, anyone can deduct 100 percent of a plane's purchase price and maintenance expenses if the plane is used for nonrecreational purposes or leased to a flight school.

(COCA, 2019, MAG)

b. Perhaps the probable incoming speaker of the Missouri House, Rep. John Diehl, would like an explanation of the concept. The concept is elegant in its simplicity and how it increases the bottom line. Rep. Diehl wants the citizens of Missouri to vote to eliminate the Missouri Lottery in 2016. His reasoning on the face of it sounds reasonable: The lottery is spending 75 percent of revenues for commissions, prizes to the winners, advertising and administration.

(COCA, 2014, NEWS)

c. As for why poems in the Kantian mold are comparatively rare at the moment, I can speculate but not much more than that. The relative ascendancy of the moral does not seem inevitable on the face of it. (COCA, 2009, ACAD)

The it used in on the face of it in (3) works as an anaphora because it refers to an already existing noun (phrase) in the contexts. For example, in (3a), it refers to a free plane, in (3b), it describes the noun phrase just prior to on the face of it (i.e., His reasoning.), and in (3c), it points out the context just prior to on the face of it: The relative ascendancy of the moral does not seem inevitable. Corpus evidence clearly demonstrates that on the face of it tends to co-occur with copular verbs and is often located at either the beginning, middle, or the end of a sentence. Semantically, on the face of it is used in a similar way to it looks like as explained in (2). When on the face of it is positioned as the beginning of a sentence, the phrase functions as a hedge connecting the utterances appearing before and after the phrase, that is, the phrase functions almost same as adverbial disjuncts or conjuncts.

(4) shows that on its face, which is fully discussed in this study, has not been accepted as the $O E D^{2}$ does not include or explain on its face.

(4) Note the following expressions where the of-construction rather than the possessive is used:

$$
\begin{aligned}
& \left.\begin{array}{l}
\text { On the face of } i t, \\
* \text { On its face, }
\end{array}\right\} \text { it seems a good idea. }
\end{aligned}
$$

(Quirk et al., 1985, p. 362) ${ }^{2}$

\subsection{Genitive and the of-Construction}

Quirk et al. (1985, p. 321) claimed that the use of the genitive was determined by a combination of structural and semantic conditions, as shown in (5).

(5) a. the meanings expressed by the relationship between the genitive noun and its head noun 
b. the type of noun taking the genitive

c. the type of noun acting as head

The genitive meanings in (5a) are shown in the following sentential or phrasal analogues: (i) possessive genitive (e.g., Mrs Johnson has a passport. -> Mrs Johnson's passport); (ii) subjective genitive (e.g., Her parents consented. -> her parents' consent); (iii) objective genitive (e.g., (...) released the boy $->$ the boy's release); (iv) genitive of origin (e.g., The girl told a story. -> the girl's story); (v) descriptive genitive (e.g., a college for women -> a women's college); (vi) genitive of measure (e.g., The absence lasted ten days. -> ten day's absence); (vii) genitive of attribute (e.g., The victim had courage. -> the victim's courage); and (viii) partitive genitive (e.g., The baby has eyes. -> the baby's eyes).

The choice of genitive in (5b) is influenced by the end-focus (or end-weight), which encourages the placing of the more complex and communicatively more important units toward the end of the noun phrase. The end-focus indicates that the genitive tends to give the information focus to the head noun, whereas the of-construction tends to give the focus to the prepositional complement, as in (6).

(6) a. The explosion damaged the ship's funnel. [funnel is the focus]

b. Having looked at all the funnels, she considered that the most handsome was the funnel of the Orion. [the Orion is the focus]

(Quirk et al., 1985, p. 323)

Some idioms require a construction in which the personal pronoun is a complement in a postmodifying of-phrase despite the end-focus, as shown in (7).

(7) a. It will be the death of me.

b. the impudence of him

c. the cheek of her

d. I don't like the taste/look/feel, etc. of it.

e. For the life of me, I cannot remember her name, and yet my memory of her is still vivid.

As in (5c), expressions with edge, end, surface, and for ... sake permit alternative of-constructions.

(8) He did it $\int$ for charity's sake.

for the sake of charity.

(Quirk et al., 1985, p. 325)

Similarly, fixed expressions such as at the river's edge, at his journey's end, for art's sake, the water's surface, and for heaven's sake can also be used in of-constructions.

\section{Research Questions}

The fixed phrase on its face has received little research attention; however, while it appears to be an opaque phrase from semantic, syntactic, formative standpoints, it is actually reasonably common. This study was driven by the following research foci using the research methods and data outlined in Sections 4 and 5.

(9) a. the semantic and syntactic features of on its face

b. the variations between on the face of it and on its face

c. how on its face was/is formed

d. the reason underlying the formation for on its face

e. the acceptability of on its face

\section{Research Method}

This study employed CPA, which is a corpus linguistics procedure that associates word meanings with word use through an analysis of phraseological patterns and collocations. CPA does not identify the meanings of a verb or noun directly; rather, the meanings are associated with prototypical sentence contexts and concordance lines are grouped into semantically motivated syntagmatic patterns. The association of a "meaning" with each pattern is the secondary step and is closely coordinated with the assignment of the concordance lines to the patterns. For example, the intransitive verb abate could be identified as having only one sense (become less in intensity) or storm abate could be separated from political protest abate because of the different implicatures. In more complex cases such as the verb bear it is important to recognize the patterns for effective disambiguation; for example, while bearing a heavy burden is a pattern that normally has an abstract interpretation in English (as opposed to, say, carrying a heavy load), the meaning is associated with the prototypical phrase, which is quite 
different from the phrase I can't bear it.

Pustejovsky et al. (2004) explained that in CPA the "meaning" of the pattern is expressed as a set of basic implicatures; for example, one pattern for the verb file is: [[Human = Plaintiff]] file [[Procedure = Lawsuit]], for which the implicature could be expressed as If you file a law suit, you are acting as the plaintiff and you activate a procedure by which you hope to obtain redress for some wrong that you believe has been done to you. Depending on the proposed application, a pattern implicature may be expressed in a variety of ways, such as a translation into another language or as a synonym set such as "file = activate, start, begin, lodge". Please see in detail about CPA: Hanks (2004), Hanks and Pustejovsky (2005).

\section{Data}

The availability of large computer corpora has made it more possible to make new phraseological research findings. To investigate the research foci outlined in (9a-e), this study used the Corpus of Contemporary American English (COCA), the British National Corpus (BNC), Word Banks Online (WB) from a synchronic perspective, and The Corpus of Historical American English (COHA) from a diachronic perspective. COCA was accessed on January 17 and 23 and February 3, 5, 7, and 18, 2020 and the BNC, WB, and COHA were accessed on February, 7 and 14, 2020. Section 6 shows the data obtained from COCA, the register and where each example is used. The acronyms $\mathrm{ACAD}=$ academic, $\mathrm{FIC}=$ fiction, $\mathrm{MAG}=$ magazine, $\mathrm{SP}=$ spoken, $\mathrm{WR}=$ written, and $\mathrm{NW}=$ news.

\section{Results for on Its Face}

The research foci outlined in (9a-e) were resolved one by one using the CPA and the corpora.

\subsection{Semantic and Syntactic Features}

What emerged clearly from the corpus shown in (10) was that on its face tended to be most used in legal contexts and tended to co-occur with legal words such as unconstitutional, invalid, and lawful positioned at the end of a sentence. The data revealed that the syntactic pattern [a word recalling legal + on its face] was prototypical and was located at the end of a clause or a sentence.

(10) a. UCLA law professor Eugene Volokh said there are other laws both at the state and federal level that prosecutors could use to file charges against members of the group. The Anti-Riot Act, on the other hand, appears to be unconstitutional on its face, but has been challenged only a few times because it's so rarely used, he said.

(COCA, 2019, NW)

b. President Trump claims the U.S. is the only country to afford birthright citizenship, which is not true. At least thirty countries do. Lawmakers have tried to revoke it in the past and the Department of Justice has said that is unconstitutional on its face.

(COCA, 2018, SP)

c. In civil proceedings, he argued, Congress could compel enforcing courts to automatically enforce regulations in most circumstances, as long as the regulation was not "invalid on its face."

(COCA, 2019, ACAD)

d. OLC's review is limited to the narrow question of whether, in OLC's view, a proposed Executive Order is lawful on its face and properly drafted.

(COCA, 2017, MAG)

e. "Senate Bill 1573 is unconstitutional on its face," the city of Corvallis alleges in its lawsuit.

(COCA, 2016, NW)

The possessive its in (10) works as an anaphora and clearly points out what something is. An examination of each example in (10) shows that: the its in (10a) indicates that the Anti-Riot Act appears to be unconstitutional, the its in (10b) that is unconstitutional, the its in (10c) that the regulation was not invalid, the its in (10d) that $a$ proposed Executive Order is lawful, and the its in (10e) that Senate Bill 1573 is unconstitutional. These syntactic features in the content before on its face appear to suggest that on its face has a similar meaning to 'it looks like $\sim$, that is, on its face functions as a hedge. In (10a), where copular verbs such as appear are observed in the sentence in which on its face is used, on its face is semantically more uncertain in terms of what the its in on its face is referring to than when it does not co-occur with copular verbs. The syntactic pattern [a copular verb $+\mathrm{a}$ word concerning legal + on its face] appears to be more of a downtoner than the prototypical syntactic pattern.

In addition to the examples in which on its face is located at the end of a clause or a sentence, it can also appear at the beginning of a sentence (11), at the middle or end of a clause (12), and at the end of a sentence (13). Please note that in (11), (12), and (13), no legal words were found around on its face.

(11) a. In his first 10 days in office, Trump signed an executive order that required all his political hires to sign a 
pledge. On its face, it's straightforward and ironclad: When Trump officials leave government employment, they agree not to lobby the agencies they worked in for five years.

$$
\text { (COCA, 2019, MAG) }
$$

b. It is a choice to embrace ritual over leisure, a sacrifice of freedom in behavior, diet, and dress for an ancient set of rules. On its face, this seems like a generation-defying choice. Young Americans are moving away from traditional religious observance in large numbers, and Jews are no exception.

(COCA, 2016, MAG)

c. The question now is: How can it make sense for Keats to imagine that his death will increase the richness of the nightingale's song? The answer, I think, is that Keats imagines that his death will increase the intensity of the experience of listening to the nightingale. That experience is rich; to become a sod would make it still richer. On its face this answer sounds absurd, but our reflections on the dynamics of Dickinson's comparison of death to absorbed listening provide us with the tools to take it seriously.

(COCA, 2016, ACAD)

As in the its in (10), the its in (11) works as an anaphora: the its in (11a) signifies an Executive Order that required all his political hires to sign a pledge; the its in (11b), a choice to embrace ritual over leisure, a sacrifice of freedom in behavior, diet, and dress for an ancient set of rules; and the its in (11c), the answer. Semantically, on its face appears to means 'seemingly.' Syntactically, it tends to be used with copular verbs. Therefore, from this dual perspective, it is apparent that the pattern [ . On its face, S + a copular verb ....] behaves as a hedge for downtoning the contents in the sentence appearing before on its face, which is the same as disjunct and conjunct adverbial functions. The pattern also appears to mean more because of the lexical meanings of the copular verbs.

The its in on its face located at the middle or end of a clause in (12) also functions as an anaphora, with the data providing evidence of a semantic and syntactic patterning that $[\mathrm{S}+($ a copular verb) + on its face ....] in which on its face means 'seemingly' and functions as a downtoner.

(12) a. In my latest Because Science, I'm taking another fascinating fan question that appears simple on its face, but quickly leads down a rabbit hole of physics.

(COCA, 2016, MAG)

b. WHD is reviewing the need for additional guidance on internships in the public and non-profit sectors. While this guidance is clear on its face, it is unfortunately only that- guidance.

(COCA, 2017, ACAD)

c. Instead of being circumspect, Cruz said quite plainly that he is positive that Trump was responsible for the rumors. He noted that "the story on its face quoted one person on the record... Trump's chief political strategist and hatchet man, Roger Stone" and noted that Trump himself had proposed that the editor of "the head of the National Enquirer, a guy named David Pecker, is good friends with Donald Trump."

(COCA, $2016 \mathrm{MAG})$

In (13), the its in on its face, which is located at the end of a sentence, functions as an anaphora, and signifies the passage before on its face: the its in (13a) indicates that Michael Collins' goal of Irish independence was noble; the its in (13b) indicates significant, and the its in (13c) indicates that the federal bailout of the big banks was outrageous. Semantically, on its face is the same as in (11) and (12). The data revealed that the syntactic pattern $[\mathrm{S}+\mathrm{V}+\mathrm{C}+$ on its face $]$ was a phraseological pattern that worked as a hedge that non-judgmentally withholds the content located before on its face.

(13) a. Michael Collins' goal of Irish independence was noble on its face. After all, a yearning for freedom runs deep in the human soul, thus he was a patriot in the eyes of many of his countrymen.

$$
\text { (COCA, 2014, MAG) }
$$

b. GWEN-IFILL: Eddie Glaude, I have to ask this. Do you think - she mentioned the fact of having the bully pulpit at the White House. Is it significant in any way that a black president would be the one heading up this initiative, and does it make a difference? Is there enough?

EDDIE-GLAUDE: Well, it's significant on its face. I hope it will play itself out in a substantive way. (COCA, 2014, SP)

c. The federal bailout of the big banks was outrageous on its face.

(COCA, 2010, ACAD)

The on its face in (14) co-occurs with the underlined negative connotational words: the its in (14a) indicates 
she's pregnant again; the its in (14b) indicates that the plan seems absurd; and the its in (14c) indicates this philosophy: all of which indicate that on its face works as an anaphora. The data provided the syntactic pattern [S + a (copular) verb + a negative connotational word + on its face] to subjectively explain the content indicated by its.

(14) a. WILLIE-GEIST: All right. Now, Jessica Simpson had been in the headlines for the pregnancy in 2012. She's pregnant again. But let's talk about her first child, Maxwell, which isn't so bad on its face; but naming a girl Maxwell is a problem?

(COCA, 2013, SP)

b. He said the plan "seems absurd on its face."

(COCA, 2016, MAG)

c. At the heart of those questions is a lurking assumption that Chaffetz brought into the light: Maybe the poor deserve their lot in life. This philosophy, while absurd on its face, effectively cripples any momentum toward helping suffering populations and is an old favorite of the Republican Party.

(COCA, 2017, MAG)

Table 1 shows the features for on its face as explained in the above examples from the corpora. On its face appears to mean 'seemingly' regardless of its location in the sentence, and plays a precursive role as it first gives superficial information about the content shown in its and then details it from a pragmatic viewpoint.

Table 1. Features of on its face from the CPA

\begin{tabular}{lllll}
\hline Pattern & $\begin{array}{l}\text { Position in a } \\
\text { sentence/clause }\end{array}$ & Frequently co-occurring words & $\begin{array}{l}\text { Contextual } \\
\text { type }\end{array}$ & Other features \\
\hline$[($ A copular verb + ) a word related with & End & $\begin{array}{l}\text { Copular verbs, } \\
\text { unconstitutional, invalid, lawful }\end{array}$ & Legal & N/A \\
legal + on its face $]$ & Copular verbs & Any & Disjunct or conjunct \\
{$[\sim$. On its face, $\mathrm{S}+$ a copular verb ....] } & Beginning & Any & N/A \\
{$[\sim($ A copular verb on its face $]$} & Middle & Copular verbs & Any & N/A \\
{$[\mathrm{S}+\mathrm{V}+\mathrm{C}$ on its face $]$} & End & Copular verbs & N/A \\
{$[\mathrm{S}+\mathrm{a}$ (copular) verb + a negative } & Middle, end & Copular verbs, bad, absurd & Any & \\
connotational word + on its face $]$ & & & & \\
\hline
\end{tabular}

\section{2 (9b) Variations Between on the Face of It and on Its Face}

As Quirk et al. (1985) suggested, as an end-focus puts the focus on it in on the face of it but face in on its face, the focal point moves, that is, for on the face of $i t$, the attention is paid to the content referred to by $i t$; therefore, the content is deemed more important than face (i.e., appearance). However, for on its face, as face is of greater importance, the its emphasizes appearance. For example, when on its face is used in a legal context, the pattern is typically $[\mathrm{S}+\mathrm{a}$ (copular) verb + unconstitutional/invalid/ lawful + on its face], which implies that the $\mathrm{S}$ (= subject) is seemingly unconstitutional/invalid/ lawful, but the speaker uses on its face as a hedge as they do not know if $\mathrm{S}$ is unconstitutional/invalid/lawful. The reason on its face is often used in legal contexts is that it might conflict with the law when making a categorical decision, as explicitly shown in (15), the lexical items for which were used with on its face and were retrieved from FIND SAMPLE (randomly chosen 200 examples) in COCA, with unconstitutional having the highest frequency.

(15) invalid, ridiculous, unconstitutional, valid

Tables 2 and 3 map the copular verbs used with on the face of it and on its face obtained from FIND SAMPLE (randomly chosen 200 examples) in COCA.

Table 2. Copular verbs used with on the face of it

\begin{tabular}{ll}
\hline A copular verb & Frequency \\
\hline Appear & 4 \\
Feel & 1 \\
Look & 4 \\
Look like & 4 \\
Seem & 27 \\
Sound & 10 \\
Sum & 50 \\
\hline
\end{tabular}


Table 3. Copular verbs used with on its face

\begin{tabular}{ll}
\hline A copular verb & Frequency \\
\hline Appear & 9 \\
Look & 3 \\
Seem & 20 \\
Sound & 4 \\
Sum & 36 \\
\hline
\end{tabular}

Tables 2 and 3 indicate that there is no difference between the copular verbs that can co-occur with on the face of it and on its face in any context, that is on the face of it and on its face appear to behave in the same way. Table 2 also shows that on its face has additional registers than just the legal register.

Therefore, the phrase transformation from on the face of it to on its face was possibly because of the move in the semantic focal point from it to face. While on its face is used to hedge in legal contexts, it was found to behave in the same way as on the face of it in normal contexts.

\section{$6.3(9 c, d)$ How on its Face Is Formed and the Reason Underlying the Formation of on Its Face}

There are two possible reasons for the transformation from on the face of it to on its face. First, familiar PU such as for the sake of $\sim$ can be equally be used as for $\sim$ 's sake; therefore, it is surmised that this type of interchange influenced the formation of on its face. The second reason is because of the end-focus, as explained in the previous sections and Quirk et al. (1985). When on its face has the same meaning as on the face of it, on its face emphasizes that the focal point for on the face of it is on face (i.e., appearance).

Underlying these two reasons is linguistic economy, whereby the simpler, more effortless expression is used when there are two expressions that syntactically and semantically behave in the same way (See Inoue, 2012, 356ff.)

\subsection{Historical Transition of on Its Face}

The COHA data on on its face indicated that on its face started being used in the 1820 s as example (16) shows.

(16) a. This decree, as appears on its face, though operating almost exclusively on American commerce, was ostensibly applicable to all nations.

(COHA, 1826, MAG)

b. The latter has been supposed by some of the British connoisseurs to be a copy by another artist, and for that reason commanded a comparatively low price at a public sale a few years ago. Its genuineness is, however, perfectly apparent on its face to all who are acquainted with the style of the great author, and its history is so well known that there can be no reasonable doubt upon the subject. (COHA, 1830 MAG)

Until the 2000s, on its face had a low frequency in $\mathrm{COHA}^{3}$, so could be said to be a stillborn PU.

\section{Substitution Tests-The Acceptability of on Its Face}

The research results in the previous sections were verified by seven native English speakers: two Americans, an Australian, two Canadians, and two English: who were asked to decide on the acceptability of (17), (18), and (19), with (17) testing the acceptability of on its face, (18) testing the acceptability of sentences in which on the face of it was replaced by on its face, and (19) testing the acceptability of sentences in which on its face was replaced with on the face of it. The results from this verification of (17), (18), and (19) are shown in Table 4.

(17) a. UCLA law professor Eugene Volokh said there are other laws both at the state and federal level that prosecutors could use to file charges against members of the group. The Anti-Riot Act, on the other hand, appears to be unconstitutional on its face, but has been challenged only a few times because it's so rarely used, he said.

b. President Trump claims the U.S. is the only country to afford birthright citizenship, which is not true. At least thirty countries do. Lawmakers have tried to revoke it in the past and the Department of Justice has said that is unconstitutional on its face.

c. In his first 10 days in office, Trump signed an executive order that required all his political hires to sign a pledge. On its face, it's straightforward and ironclad: When Trump officials leave government employment, they agree not to lobby the agencies they worked in for five years.

d. It is a choice to embrace ritual over leisure, a sacrifice of freedom in behavior, diet, and dress for an ancient set of rules. On its face, this seems like a generation-defying choice. Young Americans are 
moving away from traditional religious observance in large numbers, and Jews are no exception.

e. In my latest Because Science, I'm taking another fascinating fan question that appears simple on its face, but quickly leads down a rabbit hole of physics.

f. WHD is reviewing the need for additional guidance on internships in the public and non-profit sectors. While this guidance is clear on its face, it is unfortunately only that - guidance.

g. Michael Collins' goal of Irish independence was noble on its face. After all, a yearning for freedom runs deep in the human soul, thus he was a patriot in the eyes of many of his countrymen.

h. GWEN-IFILL: Eddie Glaude, I have to ask this. Do you think-she mentioned the fact of having the bully pulpit at the White House. Is it significant in any way that a black president would be the one heading up this initiative, and does it make a difference? Is there enough?

EDDIE-GLAUDE: Well, it's significant on its face. I hope it will play itself out in a substantive way.

i. WILLIE-GEIST: All right. Now, Jessica Simpson had been in the headlines for the pregnancy in 2012. She's pregnant again. But let's talk about her first child, Maxwell, which isn't so bad on its face; but naming a girl Maxwell is a problem?

j. He said the plan "seems absurd on its face."

(18) a. The inventory of used aircraft was too high, and it created a disparity in value that hurt sales of new planes, he said. It may seem tantalizing to use this tax deduction as a way to get a free plane, but it's not that simple. On its face, anyone can deduct 100 percent of a plane's purchase price and maintenance expenses if the plane is used for nonrecreational purposes or leased to a flight school.

b. Perhaps the probable incoming speaker of the Missouri House, Rep. John Diehl, would like an explanation of the concept. The concept is elegant in its simplicity and how it increases the bottom line. Rep. Diehl wants the citizens of Missouri to vote to eliminate the Missouri Lottery in 2016. His reasoning on its face sounds reasonable: The lottery is spending 75 percent of revenues for commissions, prizes to the winners, advertising and administration.

c. As for why poems in the Kantian mold are comparatively rare at the moment, I can speculate but not much more than that. The relative ascendancy of the moral does not seem inevitable on its face.

(19) a. In civil proceedings, he argued, Congress could compel enforcing courts to automatically enforce regulations in most circumstances, as long as the regulation was not "invalid on the face of it."

b. OLC's review is limited to the narrow question of whether, in OLC's view, a proposed Executive Order is lawful on the face of it and properly drafted.

c. The question now is: How can it make sense for Keats to imagine that his death will increase the richness of the nightingale's song? The answer, I think, is that Keats imagines that his death will increase the intensity of the experience of listening to the nightingale. That experience is rich; to become a sod would make it still richer. On the face of it, this answer sounds absurd, but our reflections on the dynamics of Dickinson's comparison of death to absorbed listening provide us with the tools to take it seriously.

d. Instead of being circumspect, Cruz said quite plainly that he is positive that Trump was responsible for the rumors. He noted that "the story on the face of it quoted one person on the record... Trump's chief political strategist and hatchet man, Roger Stone" and noted that Trump himself had proposed that the editor of "the head of the National Enquirer, a guy named David Pecker, is good friends with Donald Trump."

e. The federal bailout of the big banks was outrageous on the face of it.

f. At the heart of those questions is a lurking assumption that Chaffetz brought into the light: Maybe the poor deserve their lot in life. This philosophy, while absurd on the face of it, effectively cripples any momentum toward helping suffering populations and is an old favorite of the Republican Party. 
Table 4. Responses to the acceptability of on its face

\begin{tabular}{lllll}
\hline & $\circ$ & $\times$ & No answer & Sum \\
\hline$(17 \mathrm{a})$ & 7 & 0 & 0 & 7 \\
$(17 \mathrm{~b})$ & 7 & 0 & 0 & 7 \\
$(17 \mathrm{c})$ & 7 & 0 & 0 & 7 \\
$(17 \mathrm{~d})$ & 4 & 0 & 3 & 7 \\
$(17 \mathrm{e})$ & 5 & 0 & 2 & 7 \\
$(17 \mathrm{f})$ & 5 & 1 & 1 & 7 \\
$(17 \mathrm{~g})$ & 5 & 0 & 2 & 7 \\
$(17 \mathrm{~h})$ & 7 & 0 & 0 & 7 \\
$(17 \mathrm{i})$ & 4 & 2 & 1 & 7 \\
$(17 \mathrm{j})$ & 7 & 0 & 0 & 7 \\
$(18 \mathrm{a})$ & 7 & 0 & 0 & 7 \\
$(18 \mathrm{~b})$ & 7 & 0 & 0 & 7 \\
$(18 \mathrm{c})$ & 4 & 1 & 2 & 7 \\
$(19 \mathrm{a})$ & 7 & 0 & 0 & 7 \\
$(19 \mathrm{~b})$ & 7 & 0 & 0 & 7 \\
$(19 \mathrm{c})$ & 7 & 0 & 0 & 7 \\
$(19 \mathrm{~d})$ & 7 & 0 & 0 & 7 \\
$(19 \mathrm{e})$ & 7 & 0 & 0 & 7 \\
$(19 \mathrm{f})$ & 7 & 0 & 0 & 7 \\
\hline
\end{tabular}

As shown in Table 4, the responses to (17) indicated that that on its face was acceptable; however, some respondents answered No or No answer for $(17 \mathrm{~d}, \mathrm{e}, \mathrm{f}, \mathrm{g}, \mathrm{i})$ as the contexts did not make sense to them although they understood on its face. When on the face of it was replaced with on its face in (18), almost all respondents regarded these as acceptable, which indicated that on the face of it could be used interchangeably with on its face. In (18c), several respondents answered No and No answer because they did not understand the context meaning but understood on its face. The responses to (19) in which on its face was replaced with on the face of it indicated that on its face was seen to be synonymous with on the face of it.

\section{Implications for Future Phraseological Research}

The phrase transformation from the of-construction to possession for the PUs discussed in this study does not appear to cause semantic confusion. For example, the of-construction for the life of me cannot change into for my life possession because for my life can be literally interpreted. Therefore, these types of phrase transformations are not arbitrary but appear to take place on semantically important elements. Therefore, with a focus on phrase transformations in other PUs, future research could analyze each type of phrase transformation to reveal the phrase change rules and clarify those phrases that can move from of-construction to possession and those that cannot.

\section{Conclusion}

This paper reviewed phrase transformations by focusing on the transformation from on the face of it to on its face. This study used the CPA to examine the incidence of phrase transformations over time, an area that has had very little past attention. Exploring phrase transformations and explaining them in theoretical and practical terms to fully clarify the transformation process remains a challenge for future phraseological research.

\section{Acknowledgements}

This research was made possible by the Grant-in-Aid for Scientific Research (C) (Grant number 20K00674). I would like to thank the Japan Society for the Promotion of Science.

\section{Corpora}

BNC: British National Corpus (http://scnweb.jkn21.com/BNC2/)

COCA: The Corpus of Contemporary American English (http://corpus.byu.edu/coca/)

COHA: The Corpus of Historical American English (http://corpus.byu.edu/coha/)

DANTE: Database of Analysed Texts of English (http://www.webdante.com/index.html.)

WB: WordBanksOnline (http://scnweb.jkn21.com/WBO2/) 


\section{Dictionaries}

MED ${ }^{2}$ : Macmillan English Dictionary for Advanced Learners, New Edition. 2007. Oxford: Macmillan Education.

OED ${ }^{2}$ : Oxford English Dictionary on Historical Principle 2nd edition on CD-ROM. (Version 2.0) 2000. Oxford: Oxford University Press.

\section{References}

Ando, S. (ed.). (2011). Sanseido Comprehensive Dictionary of English Idioms and Phrasal Verbs. Tokyo: Sanseido.

Bybee, J. (2015). Language Change. Cambridge: Cambridge University Press. https://doi.org/10.1017/CBO9781139096768

Hanks, P. (2004). Corpus pattern analysis. European Association for Lexicography's Proceedings, 1, 87-98.

Hanks, P., \& Pustejovsky, J. (2005). A pattern dictionary for natural language processing. Revue Francaise de Langue Appliquée, 10(2). https://doi.org/10.3917/rfla.102.82

Inoue, A. (2007). Present-Day Spoken English: A Phraseological Approach. Tokyo: Kaitakusha.

Inoue, A. (2011). A phraseological approach to finding the functions of newly observed compound prepositional phrases until to and up until to in contemporary English. In Lexicography: Theoretical and Practical Perspective (pp. 160-169) (ASIALEX (Asian Association for Lexicography)'11 Proceedings).

Inoue, A. (2012). Influences on the formation of new phraseological units observed in contemporary English: least effort and redundancy. In A. Inoue \& T. Kanzaki (Eds.), Aspects of English Studies in the 21st Century - Linguistic and Cultural (pp. 357-378). Tokyo: Kaitakusha.

Inoue, A. (2018a). Newly established idioms through the blending of semantically similar idioms-take care for, take care about, and care of (pp. 1-24). Lexicon, No. 48.

Inoue, A. (2018b). Working toward the Systematization of English Phraseology from the Three Perspectives of Morphology, Semantics, and Acoustic Phonetics. Tokyo: Kenkyusha.

Inoue, A. (2019). English phraseological research on until by/before working as complex prepositions. International Journal of English Linguistics, 9(1), 1-14. https://doi.org/10.5539/ijel.v9n1p1

Inoue, A. (2020a in press). A lexical priming's analysis of semantically similar group prepositions in formal English (pp. 1-23). Lexicon, No. 50.

Inoue, A. (2020b in press). The decision-making of selecting pronouns due to psycological distance and level of abstraction - in the case of they who, these who, those who implying people. Collected papers from Kansai Linguistic Society for English Grammar and Usages. Tokyo: Kaitakusha.

Konishi, T. (ed.) (2001). A Dictionary of English Word Grammar on Nouns. Tokyo: Kenkyusya syuppan.

Pustejovsky, J., Hanks, P., \& Rumshisky. A. (2004). Automated induction of sense in context. COLING 2004. Switzerland: Geneva. https://doi.org/10.3115/1220355.1220488

Quirk, R., Greenbaum, S., Leech, G., \& Svartvik, J. (1985). A Comprehensive Grammar of the English Language. London: Longman.

\section{Notes}

Note 1. The face used in on its face, which is discussed in this study, implies 'appearance'; therefore, when on its face co-occurs with a verb (phrase) such as lie on its face and fall flat on its face, the face does not imply 'appearance.'

Note 2. Quirk et al. (1985, p. 362) mentioned that the of-construction rather than possessive is implied in the following expressions.

I can't understand it $[$ for the life of me.

$\{$ *for my life.

I don't trust the likes of him, this will be the death of me.

To the best of my knowledge, data obtained from COCA shows that for the life of me does not transform for my life because for my life can be literally interpreted rather than being a connotation. 
Note 3. The usage rates for 'on its face' meaning 'it looks like' in each decade were as follows: $50 \%$ in $1820 \mathrm{~s}, 64 \%$ in $1830 \mathrm{~s}, 58 \%$ in $1840 \mathrm{~s}, 75 \%$ in $1850 \mathrm{~s}, 56 \%$ in $1860 \mathrm{~s}, 52 \%$ in $1870 \mathrm{~s}, 50 \%$ in $1880 \mathrm{~s}, 41 \%$ in $1890 \mathrm{~s}, 48 \%$ in $1900 \mathrm{~s}$, $62 \%$ in $1910 \mathrm{~s}, 65 \%$ in $1920 \mathrm{~s}, 24 \%$ in $1930 \mathrm{~s}, 41 \%$ in $1940 \mathrm{~s}, 36 \%$ in $1950 \mathrm{~s}$ 代, $24 \%$ in $1960 \mathrm{~s}, 50 \%$ in $1970 \mathrm{~s}, 47 \%$ in $1980 \mathrm{~s}, 47 \%$ in $1990 \mathrm{~s}$, and $57 \%$ in $2000 \mathrm{~s}$.

\section{Copyrights}

Copyright for this article is retained by the author, with first publication rights granted to the journal.

This is an open-access article distributed under the terms and conditions of the Creative Commons Attribution license (http://creativecommons.org/licenses/by/4.0/). 